\title{
Clinical Research and its Condition in India
}

\section{Geetanjali Murari*}

PGD in Clinical Data Management, Hazaribag, Jharkhand

India has become a global hub for outsourcing clinical trials for many pharma giants situated in developed countries. The reason for this is quite understandable. We are a country with a large pool of heterogeneous patients, large number of medical expertise with English dialect, increasing rates of hospitals with good infrastructure and medical equipments. But the most important reason is low cost. The cost of clinical trial is reduced up to $60 \%$ when compared to other countries. For instance, trials for a standard drug in the United States can cost about $\$ 150$ million. A similar drug could be tested in India at a 60 per cent reduction of that whopping cost. In addition to that we have got some good regulatory authority set up in our country. Central Drug Standard Control Organisation (CDSCO) looks after every loophole in the system. We have our own regulation like Schedule Y to regulate the trial and guidelines such as ICMR, Indian GCP. The trials conducted in India are certified and approved by international guidelines and regulations, like, ICH and FDA. We have strict audit and inspection facilities. IRB/IEC is set up in the institutes to screen the whole trial. The selection procedure of Ethics Committee is quite complex to have a right say. All these factors attract other countries to perform their trials in India. The pace for drug trials in the country is so fast that the Clinical Data Interchange Standards Consortium (CDISC), USA, a non-profit organization committed to the development of clinical research organizations' standards the world over, is looking at setting up its chapter in India.

But in spite of all these boundaries it is said that the subjects/ volunteers are used as 'guinea pigs' in the clinical trial. The stringent screening procedure, informed consent process, inclusion and exclusion criteria are not sufficient in saving the lives of these subjects. It was quoted that in 2011, 438 cases of Serious Adverse Event (SAE) were reported of which 16 were found to be due to clinical trials. The previous year, 668 cases of SAE were reported of which 22 were caused due to the trials. These deaths could be related to diseases or administration of drugs and its side- effects. Investigators should confirm and report the reason of adverse event to the sponsor and regulatory authority in the given time period and quick action must be enforced in such cases.

Some people also talk about increasing the compensation of the volunteers. But that again would be an inhumane act to determine the price of human life. Otherwise, lower section of our society could probably put their life at stake for monetary advantages. Compensation should never be increased in terms of monetary value. The compensation should always be fair and equitable, like, the trial subjects should be exempted from hospital charges, medical facilities, treatment, drugs, etc during the trial and follow up period with some reasonable amount.

The answer is not in shackling clinical trials, it will only result in denying better and cheaper drugs to millions of Indian patients. All drugs need to be tested on ethnic populations to ensure their safety and efficacy, so Indian patients must have representation in trials. Genetic variations can result in different levels of drug efficacy and hence the need for local clinical trials is always required. For e.g. the cancer drug Iressa worked well in Japanese population but not so in Caucasians, which led to the identification of a gene mutation that determined response. Moreover, some diseases are more prevalent in India. These range from malaria and chikunguniya to tuberculosis, kala azar and head and neck cancer. Drugs for such diseases can be best tested in India only.

Now, it is the time when we must include some technologies to increase the vigilance power at the site where clinical trials are conducted. It should be made mandatory for drug investigators to video record the procedure of informed consent of participants in a clinical trial. This would protect the drug-naive Indians from becoming guinea pigs in global clinical trials. The Union health ministry will soon issue a draft notification, according to which drug investigators will have to video record trial subjects giving their informed consent for the study. The Drug Technical Advisory Board (DTAB) in its recent meeting said that a video recording will authenticate that at the time of enrolment, proper care was taken while informing the subject about the pros and cons of the clinical trial and their participation in the trial was voluntary. DTAB has recommended that Schedule Y should be amended and the following clause, "An audio/video recording of the informed consent process of individual subject including procedure of providing information to the subject and his understood consent shall be maintained by the investigator for record" must be inserted. The trial subject should be made aware about the new drug and its first time administration in humans, its therapeutic efficacy and serious adverse reactions during the trial. Uninformed consent is a serious threat to the volunteers taking part in the trials. The effective CCTV camera should be installed at the trial site to administer the whole procedure of trial. This would help the ethics committee and regulatory authority to investigate the matter more efficiently. Union health ministry says every approval/permission for conducting clinical trials now includes a condition that in case of study related injury or death; applicant will provide complete medical care as well as compensation for the injury or death which has been incorporated in the informed consent form. Now, registration of clinical trials in the Clinical Trail Registry of the Indian Council of Medical Research is mandatory. India has set up 12 new drug advisory committees to advice on matters to review clinical trials.

India is seen to be an attractive hub for drug innovation based on our cost and skills. However, out of over 1, 00,000 human trials being conducted in 178 countries, less than 2,000 (2\%) are being done in India compared to over 9,000 (9\%) in China.

Blame it on lack of credible regulation. The fact is that our current

*Corresponding author: Geetanjali Murari, PGD in Clinical Data Management, Hazaribag, Jharkhand, Tel: 9030523204; E-mail: geetanjali1232@gmail.com

Received February 02, 2013; Accepted May 27, 2013; Published June 17, 2013

Citation: Murari G (2013) Clinical Research and its Condition in India. J Clinic Res Bioeth 4: 146. doi:10.4172/2155-9627.1000146

Copyright: (c) 2013 Murari G. This is an open-access article distributed under the terms of the Creative Commons Attribution License, which permits unrestricted use, distribution, and reproduction in any medium, provided the original author and source are credited. 
legal framework is strong enough to ensure transparency and ethical practices during the conduct of clinical trials. Instead of dismissing clinical trials, we need to plug the loopholes and implement existing laws stringently to ensure that clinical trials are conducted with utmost transparency and diligence. If we curtail clinical trials and pharma companies move to China, South Korea and other East and South Asian countries, as they are doing, we would end up losing our clients which would be a huge loss to our country. 